\section{Psychiatric aspects of urinary incontinence in women attending an outpatient urodynamic clinic}

\section{K R W Norton, A V Bhat, S L Stanton}

St George's Hospital Medical School, London SW17 0QT

$\mathrm{K} \mathrm{R}$ W Norton, $\mathrm{MD}$, lecturer in psychiatry

A V Bhat, MSc, biostatistician

S L Stanton, FRCS, senior

lecturer in obstetrics and

gynaecology

Correspondence to: Dr K R W Norton, Henderson Hospital, Surrey SM2 5LT.

BrMed f 1990;301:271-2
Urinary incontinence affects roughly $8 \%$ of women aged 16 to $64 .^{1}$ Two syndromes, genuine stress incontinence and detrusor instability (motor urge incontinence), account for most cases. In patients with detrusor instability the bladder and urethral sphincter are usually intact but uninhibited detrusor contractions occur. In the absence of structural abnormality detrusor instability may be considered to be psychosomitic: some studies have indicated an association between psychiatric symptoms and detrusor instability and have suggested that psychiatric factors play an aetiological part in the development of detrusor instability. Few such studies included control groups of women with urinary incontinence or used standardised psychiatric measures or clearly defined diagnostic categories. We undertook a study to determine whether detrusor instability is associated with a higher prevalence of psychiatric symptoms compared with other categories of incontinence.

\section{Patients, methods, and results}

One hundred and seventeen women attending an outpatient urodynamic clinic for the first time were psychiatrically assessed before their first clinical evaluation; this ensured blindness to the urological diagnosis, which was based on the results of urodynamic investigation. The women were selected over two years by taking those with a predetermined appointment time, which minimised the possibility of selection bias. Assessments took about 45 minutes.

The patients' psychiatric state was assessed by the present state examination, ${ }^{2}$ Eysenck personality inventory, ${ }^{3}$ and state-trait anxiety index. ${ }^{4}$ Other information was obtained, including demographic data, past and current medical and psychiatric history, the psychiatric history of the family, and aspects of past and present relationships within and outside the family. The duration of urinary incontinence and its severity (as reflected by the use of absorbent pads and other appliances to cope with incontinence and by the social maladjustment it caused) were also recorded. An accurate diagnosis was made in the urodynamic clinic by twin channel subtracted cystometry with uroflowmetry or videocystourethrography as a clinical diagnosis alone is unreliable.

Thirty three patients had detrusor instability and 45 genuine stress incontinence. Twenty seven patients had no detectable abnormality on urodynamic investigation. Twelve patients were excluded from the analyses: eight did not undergo urodynamic investigation and could not be assigned to a diagnostic category; one because her case notes, containing results of investigations, could not be traced; and three had voiding difficulties. Analysis of variance, analysis of covariance, and $\chi^{2}$ tests were used as appropriate to test across the groups. When there was a significant difference in the means overall Scheffe's test, which corrects the probability for multiple comparisons, was used to find any differences between pairs of means. The table summarises the results for the three groups.

\section{Comment}

Our results contradict the view that patients with detrusor instability have more psychiatric morbidity than other incontinent patients. This we believe to reflect our methodology, which incorporated standardised measures, control groups, and defined diagnostic entities. Neither the self rating Eysenck personality inventory and state-trait anxiety index nor the observer rated present state examination showed significant differences between the groups with detrusor instability and genuine stress incontinence. An unexpected finding of particular interest, however, was the high scores of the patients in whom no abnormality was detected on urodynamic investigation; their scores fell within the range for psychiatric outpatients. Furthermore, a significantly greater proportion had been treated by a psychiatrist. This group of patients merits further urological and psychiatric study.

The finding that obstetric complications had occurred at the birth of a high proportion of the patients with detrusor instability (49\%) is curious. Patients who were uncertain whether such complications had occurred were treated, for the purpose of analysis, as having had none. The reliability of such information, however, must be questioned. In some cases of detrusor instability minimal pyramidal dysfunction is found. ${ }^{5}$ Thus possibly some of the women with detrusor instability had sustained neuronal damage perinatally. This finding, taken with the similarity of the results of psychiatric assessment in the

Medical history and psychiatric state of 117 women attending urodynamic clinic according to diagnosis; where appropriate 95\% confidence intervals are given in parentheses

\begin{tabular}{|c|c|c|c|c|c|}
\hline & \multicolumn{3}{|c|}{ Diagnosis } & \multirow[b]{2}{*}{$\mathrm{p}$ Value } & \multirow[b]{2}{*}{$\begin{array}{l}\text { Pairs of groups with significantly } \\
\text { different means (Scheffe's test) }\end{array}$} \\
\hline & $\begin{array}{l}\text { Detrusor instability (DI) } \\
\qquad(\mathrm{n}=33)\end{array}$ & $\begin{array}{l}\text { Genuine stress incontinence } \\
\qquad(\mathrm{GSI})(\mathrm{n}=45)\end{array}$ & $\begin{array}{l}\text { No abnormality detected } \\
(\text { NAD })(n=27)\end{array}$ & & \\
\hline Mean age (years) & $44.9(40 \cdot 8$ to 48.9$)$ & $48 \cdot 5(45 \cdot 6$ to $51 \cdot 4)$ & $41 \cdot 2(36 \cdot 9$ to $45 \cdot 5)$ & $<0.05^{\star}$ & GSI $v$ NAD \\
\hline $\begin{array}{l}\text { Medical and psychiatric history }(\mathrm{No}(\%)): \\
\text { Obstetric complications at birth } \\
\text { One or more pregnancies } \\
\text { Treated by psychiatrist } \\
\text { Mean duration of incontinence (years) }\end{array}$ & $\begin{array}{c}16(49) \\
23(70) \\
4(12) \\
13 \cdot 4(7 \cdot 9 \text { to } 18 \cdot 9)\end{array}$ & $\begin{array}{c}7(16) \\
40(89) \\
7(16) \\
6 \cdot 8(4 \cdot 4 \text { to } 9 \cdot 2)\end{array}$ & $\begin{array}{c}2(7) \\
24(89) \\
10(37) \\
7 \cdot 9(3 \cdot 9 \text { to } 11.9)\end{array}$ & $\begin{array}{l}<0.001 \ddagger \\
<0.05 \ddagger \\
<0.05 \ddagger \\
<0.05^{\star}\end{array}$ & DI $v$ GSI \\
\hline $\begin{array}{r}\text { Severity of incontinence }(\mathrm{No}(\%)) \text { : } \\
\text { Use of aids greater than minimal } \\
\text { Secondary social maladjustment }\end{array}$ & $\begin{array}{l}29(88) \\
26(79)\end{array}$ & $\begin{array}{l}39(87) \\
35(78)\end{array}$ & $\begin{array}{l}22(82) \\
18(67)\end{array}$ & $\begin{array}{r}0.76 \ddagger \\
<0.05 \ddagger\end{array}$ & \\
\hline $\begin{array}{l}\text { Mean score on Eysenck personality inventory: } \\
\text { Neuroticism } \\
\text { Extraversion } \\
\text { Lie }\end{array}$ & $\begin{array}{c}11 \cdot 3(9 \cdot 6 \text { to } 12 \cdot 9) \\
12 \cdot 1(10 \cdot 5 \text { to } 13 \cdot 7) \\
3 \cdot 9(3 \cdot 3 \text { to } 4 \cdot 5)\end{array}$ & $\begin{array}{c}11 \cdot 7(10 \cdot 1 \text { to } 13 \cdot 3) \\
11 \cdot 5(10 \cdot 4 \text { to } 12 \cdot 6) \\
4 \cdot 1(3 \cdot 5 \text { to } 4 \cdot 7)\end{array}$ & $\begin{array}{l}14 \cdot 9(13 \cdot 2 \text { to } 16 \cdot 6) \\
10 \cdot 7(8 \cdot 9 \text { to } 12 \cdot 5) \\
3 \cdot 7(3 \cdot 0 \text { to } 4 \cdot 4)\end{array}$ & $\begin{array}{r}<0.01 \dagger \\
0.47 \dagger \\
0.82 \dagger\end{array}$ & $\mathrm{DI} v \mathrm{NAD}, \mathrm{GSI} v \mathrm{NAD}$ \\
\hline $\begin{array}{l}\text { Mean score on state-trait anxiety inventory: } \\
\text { State anxiety } \\
\text { Trait anxiety }\end{array}$ & $\begin{array}{l}36 \cdot 9(33 \cdot 3 \text { to } 40 \cdot 5) \\
38 \cdot 4(34.8 \text { to } 42 \cdot 0)\end{array}$ & $\begin{array}{l}39 \cdot 7(36 \cdot 2 \text { to } 43 \cdot 2) \\
37 \cdot 2(34 \cdot 6 \text { to } 39 \cdot 8)\end{array}$ & $\begin{array}{l}44 \cdot 1(39 \cdot 3 \text { to } 48 \cdot 9) \\
43 \cdot 8(39 \cdot 8 \text { to } 47 \cdot 8)\end{array}$ & $\begin{array}{r}0 \cdot 07 \dagger \\
<0.05 \dagger\end{array}$ & GSI $v$ NAD \\
\hline $\begin{array}{l}\text { Present state examination: } \\
\text { Mean total score } \\
\text { No }(\%) \text { defined as cases (index of definition }>5 \text { ) }\end{array}$ & $\begin{array}{c}5 \cdot 6(3 \cdot 7 \text { to } 7 \cdot 5) \\
6(18)\end{array}$ & $\begin{array}{c}4 \cdot 6(3 \cdot 2 \text { to } 6 \cdot 0) \\
6(13)\end{array}$ & $\begin{array}{c}8 \cdot 9(5 \cdot 8 \text { to } 12 \cdot 0) \\
10(37)\end{array}$ & $\begin{array}{l}<0.01 \dagger \\
<0.05 \ddagger\end{array}$ & GSI $v$ NAD \\
\hline
\end{tabular}


women with detrusor instability and those with genuine stress incontinence, suggests that future research into aetiological factors of detrusor instability should concentrate on physical, and particularly neurological, aspects.

I Thomas TM, Plymat KR, Blannin J, Meade TW. Prevalence of urinary incontinence. Br.Med J 1980;281:1243-5.

\section{Mortality in patients with bleeding peptic ulcer when those aged 60 or over are operated on early}

\author{
K E Wheatley, J H Snyman, S Brearley, \\ M R B Keighley, P W Dykes
}

\section{Department of \\ Gastroenterology, General \\ Hospital, Birmingham \\ B4 6NH \\ K E Wheatley, FRCS, research registrar \\ J H Snyman, FRCS, research \\ registrar \\ S Brearley, FRCS, research \\ registrar \\ M R B Keighley, FRCS, \\ professor of surgery \\ P W Dykes, FRCP, consultant \\ physician}

Correspondence to: $\mathrm{Dr}$ Dykes.

BrMed f 1990;301:272 dismissed as inevitable, and death rates of around $10 \%$ not in those under 60 ; we achieved a mortality of $4 \%$ in
2 Wing JK, Cooper JE, Sartorius N. The measurement and classification of psychiatric symptoms. Cambridge: Cambridge University Press, 1974

3 Eysenck HJ, Eysenck SBG. Manual of the Eysenck personality inventory. London: Hodder and Stoughton, 1978.

4 Spielberger $\mathrm{CD}$, Gorsuch RL, Lushene RE. The state-trait anxiety inventory. Palo Alto: Consulting Psychologists Press, 1970.

5 Thomas DG, Davies-Jones GAB, Clarke SJ. Urinary incontinence and minimal pyramidal disease. $\mathrm{Br} \mathcal{F}$ Urol 1980;52:460-2.

(Accepted 9 May 1990)
Death from bleeding peptic ulceration is too easily indicate unacceptable clinical practice. Endoscopic haemostasis improves results, ' but improvement can be achieved more simply. We reported previously that early surgery improves results in elderly patients but patients over 60 treated with early surgery. ${ }^{2}$ We closed the trial mainly because of the difficulty of holding six surgical firms to a fixed randomisation policy in the face of a considerable difference in mortality in patients aged 60 or over between the two treatment policies being compared ( $4 \%$ with early operation compared with $15 \%$ with delayed operation); this decision was criticised. ${ }^{3}$ We subsequently adopted the policy associated with the lowest mortality, although we no longer regarded the stigmata of recent haemorrhage as an indication for surgery as there is now doubt whether they carry the hazard once thought. ${ }^{+}$We have audited 342 consecutive patients with defined ulcer bleeding over the subsequent five years. We did not exclude patients even if they had severe coincident malignant disease or were moribund; we do not know of a larger study done in a single hospital.

\section{Patients, methods, and results}

We reviewed all patients admitted with upper gastrointestinal bleeding due to proved peptic ulceration from January 1984 to December 1988 (342 patients; 351 admissions). Altogether 214 patients were aged 60 or over. Two hundred and eighteen patients bled from duodenal ulcers or ulcers of the pyloric channel and 124 from gastric ulcers; all were examined by gastroscopy.

Patients were operated on immediately if they had exsanguinating haemorrhage or if a spurting vessel was seen at endoscopy. Patients aged 60 or over were operated on if one episode of rebleeding occurred in hospital, four units of blood or colloid were transfused for initial volume replacement or eight units of blood or colloid were transfused over 48 hours. Younger patients were operated on if two episodes of rebleeding occurred in hospital, eight units of blood or colloid were transfused for initial volume replacement or 12 units of blood or colloid were transfused over 48 hours. Patients were given prophylactic antibiotics and subcutaneous heparin and operated on by experienced surgeons and anaesthetists.

Sixty nine patients fulfilled the criteria for emergency operation, comprising 35 of the 218 with duodenal ulcers and 34 of the 124 with gastric ulcers. Fifty two (24\%) of the 214 patients aged 60 or over were operated on, compared with $17(13 \%)$ of the 128 younger patients. The most common operation for duodenal ulcer was vagotomy and pyloroplasty (21), and the most common operations for gastric ulcer were Billroth I gastrectomy (11) and vagotomy and pyloroplasty with excision of the ulcer (9). In four patients with duodenal ulcer and five with gastric ulcer the only operation was underrunning of the ulcer.

Thirteen patients died from proved haemorrhage of peptic ulcer, a mortality of $4 \%$; the mortality rose with age to $8 \%$ in those aged 80 or over (table). Four of these

Mortality in patients with bleeding duodenal or gastric ulcer according to age

\begin{tabular}{|c|c|c|c|c|c|}
\hline \multirow{2}{*}{$\begin{array}{c}\text { Age } \\
\text { (years) }\end{array}$} & \multicolumn{2}{|c|}{ Site of ulcer } & \multirow{2}{*}{$\begin{array}{c}\text { All } \\
\text { patients }\end{array}$} & \multirow[b]{2}{*}{ Deaths } & \multirow{2}{*}{$\begin{array}{c}\text { Mortality } \\
(\%)\end{array}$} \\
\hline & Duodenum & Stomach & & & \\
\hline$<50$ & 59 & 14 & 73 & & \\
\hline $50-59$ & 32 & 23 & 55 & 1 & 2 \\
\hline $60-69$ & 57 & 37 & 94 & 3 & 3 \\
\hline $70-79$ & 45 & 39 & 84 & 6 & 7 \\
\hline$\geqslant 80$ & 25 & 11 & 36 & 3 & 8 \\
\hline Total & 218 & 124 & 342 & 13 & 4 \\
\hline
\end{tabular}

deaths were in patients with advanced malignancy and two were linked with terminal vascular disease; active treatment was withdrawn in all. Two postoperative deaths occurred (operative mortality $3 \%$ ), both in patients with severe coincident disease. Thus in patients not dying from other disease and in whom resuscitation was attempted mortality from bleeding peptic ulcer was $2 \%(7 / 342)$. Contributory factors to death included cardiac failure (two patients), cerebrovascular accident (three), respiratory failure (one), and cardiac arrest at endoscopy (one). Nine operations were done for exsanguinating haemorrhage or spurting vessels, 54 for further haemorrhage, and six when transfusion limits were exceeded.

\section{Comment}

No magical formula exists for reducing the mortality of a disease. In patients with gastrointestinal haemorrhage mortality is low when a logical protocol is adhered to strictly. Our mortality of $4 \%(6 \%$ in patients aged 60 or over) could be achieved in any district general hospital by applying this protocol. ${ }^{5}$ In addition, senior surgeons and anaesthetists should not delegate an operation to inexperienced doctors.

1 Steele RJC. Endoscopic haemostasis for non-variceal upper gastrointestinal haemorrhage. Br f Surg 1989;76:219-25.

2 Morris DL, Hawker PC, Brearley S, Simms M, Dykes PW, Keighley MRB. Optimal timing of operation for bleeding peptic ulcer: prospective randomised trial. Br Med f 1984;288:1277-80.

Langman MJS. Optimal timing of operation for bleeding peptic ulcer. Br Med 1984;288:1761.

4 Garrigues-Gil V, Clamp SE, Morgan AG, Ohmann C, De Dombal FT. Do the stigmata of recent haemorrhage have additional prognostic value in patients with bleeding duodenal ulcer? Scand f Gastroenterol 1988;23 (suppl 144): 59-62.

5 Holman RAE, Davis M, Gough KR, Gartell P, Britton DC, Smith RB. Value of a centralised approach in the management of haematemesis and melaena: experience in a district general hospital. Gut 1990;31:504-8. 